\title{
Peptide nucleic acid-based targeting of microRNAs: possible therapeutic applications for glioblastoma
}

\author{
Roberto Gambari ${ }^{1,2}$, Jessica Gasparello ${ }^{1}$, Alessia Finotti ${ }^{1}$ \\ 'Department of Life Sciences and Biotechnology, University of Ferrara, Ferrara 44121, Italy. \\ ${ }^{2}$ Interuniversity Consortium for Biotechnology (CIB), Trieste 34149, Italy.
}

Correspondence to: Prof. Roberto Gambari, Department of Life Sciences and Biotechnology, University of Ferrara, Via Fossato di Mortara 74, Ferrara 44121, Italy. E-mail: gam@unife.it

How to cite this article: Gambari R, Gasparello J, Finotti A. Peptide nucleic acid-based targeting of microRNAs: possible therapeutic applications for glioblastoma. J Cancer Metastasis Treat2019;5:55. http://dx.doi.org/10.20517/2394-4722.2019.18

Received: 25 Feb 2019 First Decision: 2 Apr 2019 Revised: 17 May 2019 Accepted: 29 May 2019 Published: 11 Jul 2019

Science Editor: Ciro Isidoro; Gianluca Gaidano Copy Editor: Cai-Hong Wang Production Editor: Jing Yu

\begin{abstract}
A large and incremental number of non-coding RNAs, including microRNAs (miRNAs) have been recently demonstrated to play a very important role in human pathologies, including cancer. Therefore, microRNAs have been proposed as therapeutic targets and molecules exhibiting anti-miRNA activity or mimicking functional miRNAs have been developed. Among biomolecules proposed in anti-miRNA therapy, peptide nucleic acids (PNAs) are appealing, in consideration of their stability and efficacy in recognizing RNA targets. PNAs against tumor associated miRNAs have proven to be efficient in inducing anti-tumor effects both in vitro and in vivo. For instance, PNAs targeting miR-155-5p are able to induce apoptosis in glioma cell lines and to enhance the sensitivity to temozolomide (TMZ) in TMZ resistant glioma cells. In vivo, PNAs anti-miR-21 were found to exhibit anti-tumor effects associated with improved survival when administered to animals with intracranial gliomas.
\end{abstract}

Keywords: Peptide nucleic acids, glioma, microRNAs, miRNA targeting, delivery, apoptosis, temozolomide

\section{MICRORNAS IN ONCOLOGY}

MicroRNAs (miRNAs) are a family of evolutionary conserved small (19 to 25 nucleotides in length) non-coding RNAs playing important roles in the post-transcriptional control of gene expression. This control is operated at the level of mRNA translation and is based on the miRNA-dependent recognition of $3^{\prime} \mathrm{UTR}$, CDS and 5'UTR mRNA sequences. This molecular recognition leads to a reduction of protein synthesis ${ }^{[1-4]}$. Single or multiple mRNAs can be targeted by a single miRNA, while a single mRNA can be recognized and 
functionally controlled by several miRNAs (eventually differentially expressed in cells of different histotype); following these considerations, it is calculated that more than $60 \%$ of human mRNAs can be considered molecular targets of miRNAs ${ }^{[5,6]}$. It has been reported in different studies and reviews that the miRNA/ mRNA interaction occurs at the level of the RNA-induced silencing complex (RISC), a ribonucleoprotein which incorporates one strand of a single-stranded RNA (in our case a microRNA), acting as a template to recognize complementary mRNA transcripts ${ }^{[1-4]}$. This molecular interaction is associated to (1) repression of translation or (2) mRNA degradation, depending on the level of miRNA complementarity with nucleotide sequences of the target $\mathrm{mRNA}^{[3,4]}$. Since their discovery and first characterization, the number of human microRNAs identified and deposited in the miRBase database (miRBase v.22, www.mirbase.org) is much more than $2600^{[7-9]}$ and the research studies on microRNAs have confirmed the very high complexity of the networks constituted by miRNAs and RNA targets ${ }^{[7]}$.

Changes of microRNA expression have been demonstrated to be associated with different human pathologies, and guided alterations of specific miRNAs have been suggested as novel approaches to develop innovative therapeutic protocols ${ }^{[10-13]}$. Several reports conclusively demonstrated that microRNAs are deeply involved in tumor onset and progression, behaving as tumor promoting miRNAs (oncomiRNA and metastamiRNAs) as well as tumor suppressor miRNAs ${ }^{[14-19]}$. In general, a miRNA able to promote cancer targets mRNA coding for tumor-suppressor proteins, while microRNAs exhibiting tumor-suppression properties usually target mRNAs coding oncoproteins ${ }^{[15]}$.

\section{Targeting oncomiRNAs and mimicking tumor-suppressor miRNAs: overcoming drug resistance}

With respect to targeting oncogenic RNAs and mimicking tumor-suppressor miRNAs in translational medicine, it should be underlined that these non-coding RNAs are suitable targets for therapeutic interventions, as summarized in Figure $1^{[10-13]}$. The use of modified miRNA mimetics, either synthetic or produced by plasmid or lentiviral vectors, might lead to potentiation of miRNA functions (miRNA replacement therapy ${ }^{[20-24]}$. In this case the miRNA replacement molecules (mimicking the miRNA functions to be up-regulated) are transfected to target cells [Figure 1A, step "a"] where interact with the mRNA to be modulated [Figure 1A, step "b"]. This interaction leads to down-regulation of this mRNA and associated suppression of protein production [Figure 1A, step " $\mathrm{c}$ ", dotted arrows]. According to this procedure, it is possible to mimic the activity of tumor-suppressor miRNAs (down-regulated in tumors) to achieve downregulation of miRNA-regulated oncogenes ${ }^{[23,24]}$.

On the contrary, forced down-regulation of miRNA biological functions can be obtained using a large variety of well-characterized miRNA-inhibitor oligomers (such as in the case of direct miRNA antisense therapy based on RNA, DNA, LNA and other DNA analogues) ${ }^{[25-31]}$, miRNA sponges ${ }^{[32-38]}$, mowers ${ }^{[39]}$ or through miRNA masking strategy that interferes with miRNA function by masking the miRNA binding site of target mRNA through hybridization with complementary molecules ${ }^{[40-42]}$ [see Table 1]. In this case the miRNA inhibitors ["a", "b" and "c" of Figure 1B, suppressing the miRNA functions to be down-regulated] are transfected to target cells where they interact with the microRNA target [Figure 1B, step "d"]. This interaction prevents the target miRNA (for instance an oncomiRNA in protocols designed to develop antitumor therapy) to bind the specific 3'UTR sequence of the regulated mRNA, causing up-regulation of this mRNA and the associated increase of protein production [Figure 1B, step " $\mathrm{e}$ "]. According to this procedure, it is possible to inhibit the activity of oncomiRNAs (up-regulated in tumors) to achieve up-regulation of miRNA-regulated tumor suppressor genes.

Interestingly, in the case of the development of anti-cancer protocols, targeting miRNAs in drug-resistant tumor cell lines has been associated with partial or total reversion of the drug-resistance phenotype, as reported in different studies ${ }^{[43-48]}$. 


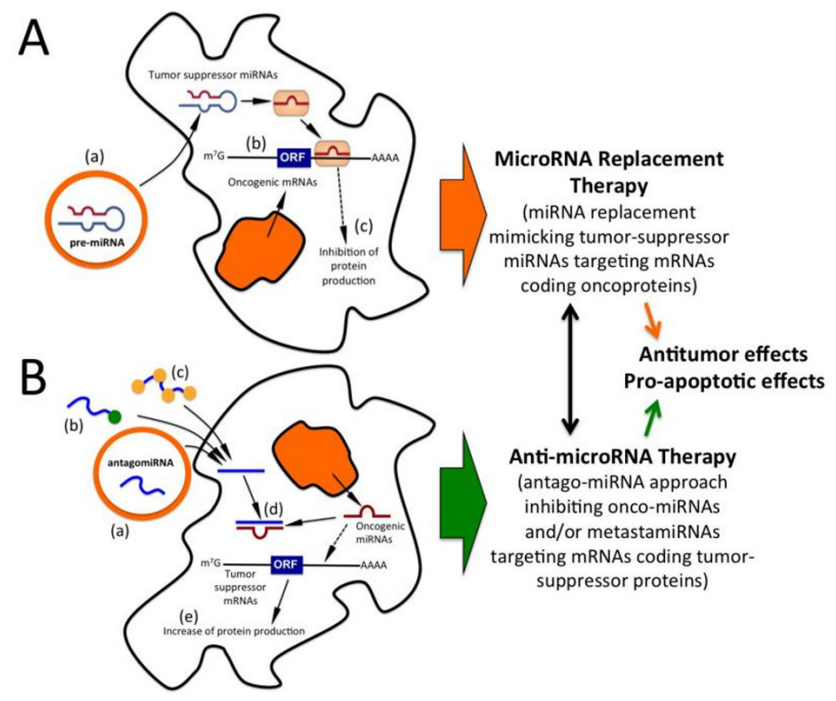

Figure 1. Scheme summarizing the miRNA replacement (A) and anti-miRNA (B) approaches to modify miRNA-regulated gene expression. In panel A the miRNA replacement molecule is transfected to target cells (a) where interact with the mRNA to be modulated (b) causing inhibition of protein production (c, dotted arrow). In panel B the miRNA inhibitors (a-c) are transfected to target cells (d) where they interact with the microRNA target preventing its binding to the specific 3'UTR sequence (dotted arrow) of the regulated mRNA (d). This causes up-regulation of this mRNA with increased protein production (e). Three examples of antagomiRNA molecules are shown: microparticle delivered antagomiRNAs (a), peptide-delivered molecules (b, peptide in green), or chemically-modified molecules (chemical modifications in yellows) to increase biological functions (for instance resistance to enzymatic degradation or delivery efficiency to target cells)

Table 1. Experimental strategies for inhibition of microRNA functions

\begin{tabular}{|c|c|c|c|c|}
\hline Strategy & Bioactive molecules & Mechanism(s) of action & Biological effects & References \\
\hline $\begin{array}{l}\text { Use of microRNA } \\
\text { inhibiting } \\
\text { molecules }\end{array}$ & $\begin{array}{l}\text { RNA, DNA, LNA and } \\
\text { other DNA analogues, } \\
\text { PNAs and PNA } \\
\text { analogues }\end{array}$ & $\begin{array}{l}\text { Sequence-specific } \\
\text { hybridization to miRNA } \\
\text { targets }\end{array}$ & $\begin{array}{l}\text { Up-regulation of the } \\
\text { expression of miRNA- } \\
\text { regulated mRNAs }\end{array}$ & $\begin{array}{l}\text { Weiler et al.. }{ }^{[25]}, 2006 ; \\
\text { Lu et al. }{ }^{[26]}, 2009 ; \\
\text { Lennox et al. }{ }^{[27]}, 2011 ; \\
\text { Obad et } a{ }^{[28]}, 2011 ; \\
\text { Elmén et al. }{ }^{[29]}, 2008 ; \\
\text { Stenvang et al. }{ }^{[30]}, 2008 ; \\
\text { Staedel et al. }{ }^{[31]}, 2015\end{array}$ \\
\hline $\begin{array}{l}\text { Use of miRNA } \\
\text { sponges }\end{array}$ & $\begin{array}{l}\text { Circular RNAs } \\
\text { (circRNAs) and long- } \\
\text { non-coding RNAs } \\
\text { (IncRNAs) }\end{array}$ & $\begin{array}{l}\text { Inhibition of miRNAs } \\
\text { by circRNA-miRNA } \\
\text { or IncRNA-miRNA } \\
\text { interactions }\end{array}$ & $\begin{array}{l}\text { Up-regulation of the } \\
\text { expression of mRNAs } \\
\text { regulated by sponged } \\
\text { miRNAs }\end{array}$ & 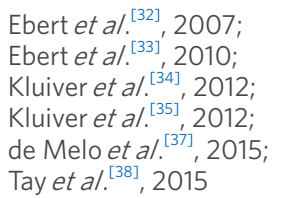 \\
\hline Use of mowers & $\begin{array}{l}\text { Synthetic devices } \\
\text { containing multiple } \\
\text { bulged miRNA binding } \\
\text { sites and named them } \\
\text { "miRNA-mowers" }\end{array}$ & $\begin{array}{l}\text { "Mowing down" miRNA } \\
\text { expression (just like a } \\
\text { lawn mower) }\end{array}$ & $\begin{array}{l}\text { Up-regulation of the } \\
\text { expression of mRNAs } \\
\text { regulated by the } \\
\text { "mowed down" miRNAs }\end{array}$ & Liu et al.. ${ }^{[39]}, 2012$ \\
\hline MirNA masking & $\begin{array}{l}\text { DNA, LNA, PNAs and } \\
\text { analogues }\end{array}$ & $\begin{array}{l}\text { Binding to mRNA and } \\
\text { interference with the } \\
\text { binding of miRNA to its } \\
\text { target site }\end{array}$ & $\begin{array}{l}\text { Up-regulation of the } \\
\text { expression of "masked" } \\
\text { mRNAs by inhibition of } \\
\text { miRNA binding }\end{array}$ & $\begin{array}{l}\text { Wang et al. }{ }^{[40]}, 2011 ; \\
\text { Bak et al. }{ }^{[41]}, 2013 ; \\
\text { Murakami et al. }{ }^{[42]}, 2014\end{array}$ \\
\hline
\end{tabular}

\section{PEPTIDE-NUCLEIC ACIDS}

Peptide Nucleic Acids (PNAs) are DNA analogues described for the first time by Nielsen et al. ${ }^{[49]}$, in which the sugar-phosphate backbone has been replaced by $\mathrm{N}$-(2-aminoethyl)glycine units ${ }^{[0-53]}$ [see Figure 2 for the chemical general structure]. PNAs are very interesting molecules for sequence-specific alteration of gene expression, since are capable of forming Watson-Crick double helices after efficient sequence-specific hybridization with complementary DNA and $\mathrm{RNA}^{[54]}$. Furthermore, they are able to generate triple helix with double-stranded DNA and to perform strand invasion ${ }^{[55]}$. In virtue of these biological activities, PNAs have 


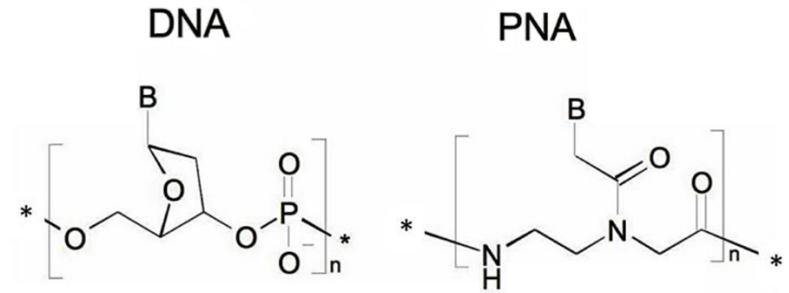

Figure 2. Scheme outlining the differences between DNA (left) and PNA (right) monomers

been demonstrated to be very efficient tools for pharmacologically-mediated alteration of gene expression, both in vitro and in vivo ${ }^{[56,57]}$.

Summarizing, PNAs and PNA-based analogues were employed as antisense molecules targeting mRNAs, triple-helix forming molecules targeting eukaryotic gene promoters, artificial promoters, decoy molecules targeting transcription factors ${ }^{[54-56]}$. Relevant in the context of the present review article, PNAs have been demonstrated to be able of altering miRNA functions, both in vitro and in vivo ${ }^{[58-62]}$. This has been recently reviewed by Manicardi et al. ${ }^{[63]}$.

While well-controlled studies are needed to compare the in vivo activity of PNAs to those of LNA, RNA and other molecules exhibiting anti-sense potential, several in vivo studies on PNAs have been already reported to sustain the usefulness of these molecules and their derivatives.

Gupta et al ${ }^{[64]}$ tried to target miR-210 with an antisense $\gamma$-peptide nucleic acids ( $\gamma$ PNAs), exhibiting superior RNA-binding affinity, improved solubility, and favorable biocompatibility. The rationale for this approach is that miR-210 is overexpressed in hypoxic cancer cells and is a key player for the adaptation of tumor cells to hypoxia. For cellular delivery, they encapsulated the $\gamma$ PNAs in poly(lactic-co-glycolic acid) (PLGA) nanoparticles. The results obtained show that $\gamma$ PNAs targeting miR-210 cause significant delay in growth of a human tumor xenograft in mice compared to conventional PNAs. Furthermore, histopathological analyses show considerable necrosis, fibrosis, and reduced cell proliferation in $\gamma$ PNA-treated tumors compared to controls ${ }^{[64]}$. In another paper, Cheng et al.$^{[1]}$ efficiently inhibited the function of oncomiRNA miR-155 in a tumor mouse model after the design and realization of a peptide-(anti-miRNA)PNA construct able to target the tumor microenvironment and to transport the anti-miRNA PNA across the cellular plasma membranes under the acidic conditions which characterize solid tumors. A final example is that published by Yan et $a l .{ }^{[65]}$, demonstrating that PNA-mediated targeting of miR-21 causes inhibition of growth and migration of breast cancer MCF-7 and MDA-MB-231 cells in vitro, and tumor growth in vivo when nude mice were employed.

\section{GLIOBLASTOMA}

Glioblastoma multiforme (GBM), a grade IV glioma, is a lethal malignant tumor accounting for $42 \%$ of the central nervous system tumors, the median survival being $12-15$ months ${ }^{[66-71]}$. The current standard therapeutic management of GBM is based on neurosurgery followed by chemoradiotherapy by fractionated external-beam radiotherapy and systemic chemotherapeutic treatment with temozolomide (TMZ) and other agents, including repurposed drugs (such as metformin, disulfiram, rapamycin and derivatives, chloroquine, ionidamine) ${ }^{[7]}$. There are only very limited possibilities for the treatment of subsequent recurrences, generally with minimal clinical efficacy ${ }^{[69]}$. Among novel therapeutic strategies for GBM, of interest are inhibitors of aberrantly activated cell signaling pathways, including those regulated by growth factors and their receptors, such as epidermal growth factor family and their receptors ${ }^{[72]}$, platelet-derived growth factors and their receptors ${ }^{[73]}$. In addition, innovative targets for GBM experimental therapy might 
be insulin-like growth factors, fibroblast growth factor and their receptors ${ }^{[74,75]}$. Excellent review articles describing current therapeutic approaches and novel trends in GBM management are available ${ }^{[69,76-82]}$.

In conclusion, since no curative treatment is available and the most used first-line drug, temozolomide (TMZ), is only able to cause an increase of the life expectancy ${ }^{[6]]}$, new drugs are urgently needed for the implementation of therapeutic protocols for anti-glioma treatments. Moreover, a high proportion of gliomas become with time TMZ-resistant. Therefore, a deep interest does exist for combined treatments on TMZ-resistant glioma cells in order to induce therapeutic relevant response, including, but not limited to, apoptosis $^{[81,82]}$.

\section{MICRORNAS IN GLIOMAS: VARIABILITY AMONG THE PATIENTS HAMPERS THE IDENTIFICATION OF POSSIBLE THERAPEUTIC TARGETS FOR PERSONALIZED TREATMENTS}

Several studies available from the recent literature clearly support the involvement of microRNAs in gliomas ${ }^{[83-93]}$, outlining a large number of miRNAs demonstrated to be dysregulated in these tumors. Of course, these studies might indicate miRNA targets to be proposed for the development of protocols for therapeutic intervention in glioma, including strategies useful to tackle the issue of drug resistance ${ }^{[94-96]}$. Comprehensive analysis of microRNA expression profile in malignant glioma tissues has been reported by Piwecka et al..$^{[97]}$, Banelli et al. ${ }^{[98]}$, Ciafrè et al. ${ }^{[99]}$. The analysis of microRNAs is also associated with tumor onset and progression. For instance a miRNA signature was found associated with glioblastoma tumor tissues. Up-regulated miRNAs were miR-221, miR-222, miR-22, miR-296-3p, miR-195, miR-155, miR-152, miR-132, miR-146b-5p, miR-149, miR-129-3p, miR-34a, miR-671-5p, miR-10a. Down-regulated miRNAs were let-7b, miR-767-5p, miR-505, miR-301b, miR-181a, miR-20a, miR-19a, miR-19b, miR-106a ${ }^{[97-99]}$. In any case, a large consensus does exist on the fact that tumor tissues are highly heterogeneous with respect to molecular and genetic features, supporting the concept that GBM represents a heterogeneous type of neoplasm when the microRNA patterns are considered ${ }^{[100,101]}$.

However, due to global high-throughput profiling it is possible to select miRNAs that are at high risk of being deregulated in the majority of patients. Thus, there is a considerable hope for utilizing miRNAs as targets in prospects of glioma therapy. A partial list of validated miRNAs dysregulated in gliomas (with their proposed mRNA targets) is reported in Supplementary Table S1.

Among the possible microRNA targets involved in glioma, miR-155-5p appears to be of relevant interest for the following reasons: (1) miR-155-5p may play an important role in the transformation of normal neural stem cell toward glioma stem cells ${ }^{[102]}$; (2) the elevated expression level of miR-155-5p promotes the proliferation and invasion of glioblastoma cells through suppressing GABA receptors ${ }^{[103]}$, FOXO3 $\mathrm{a}^{[104]}$ and MXI $1^{[105]}$; (3) an oligonucleotide targeting miR-155-5p was shown to sensitize glioma cells to taxol-induced apoptotic death ${ }^{[106]}$; and (4) miR-155-5p overexpression is considered as a major molecular feature of glioblastoma, which can discriminate this malignancy from a similar intracranial tumor, oligodendroglioma ${ }^{[107]}$. Therefore, miR$155-5 \mathrm{p}$ alone or together with other miRNAs is a predictive biomarker for glioma prognosis ${ }^{[107,108]}$. On the other hand, glioma-targeting therapy based on miR-155-5p anti-oligonucleotides is believed to be efficient to inhibit the progression of glioma ${ }^{[109]}$.

However, several recent studies have pointed out that the translation of the analysis of the expression and content of miR-155-5p and other miRNAs in gliomas into therapeutic strategy is hampered by the high variability of microRNAs among patients ${ }^{[92,100,101]}$. For instance, in analyzing 31 tumor specimens against paired normal tissue, Yan et al ${ }^{[92]}$ found a significant upregulation of miR-155 in tumor tissues. This study was based on the analysis of surgically dissected glioma specimens and their surrounding brain tissues. In spite of the increased miR-155 expression, a large proportion of tumor samples exhibited a nearly normal 


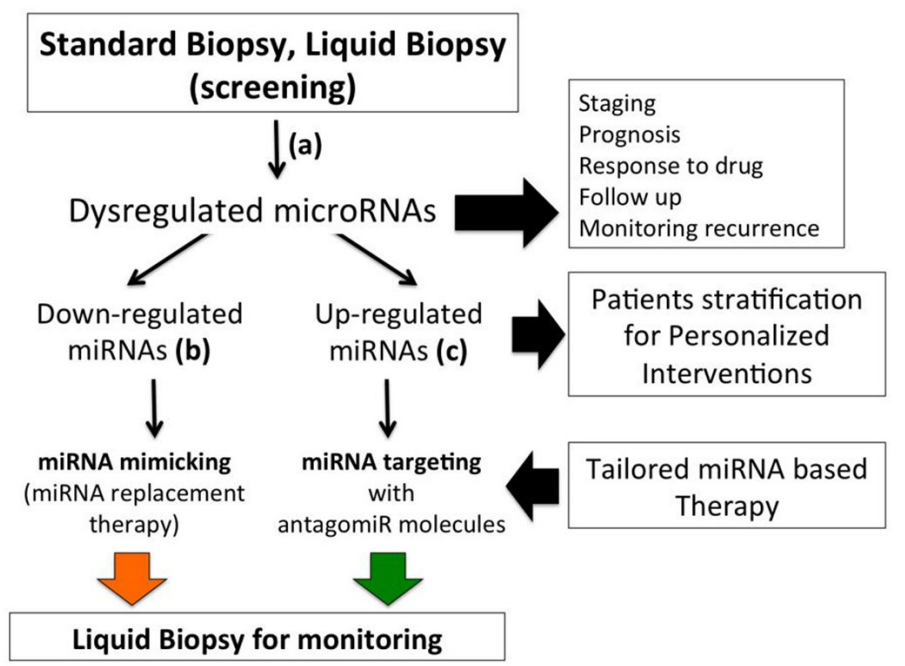

Figure 3. Scheme outlining the strategy to identify dysregulated microRNAs (a) in tumor patients and design possible therapeutic approaches based on anti-miRNA therapy and miRNA-replacement. The activity of down-regulated miRNA might be replaced with the use of miRNA mimicking molecules (b); the activity of up-regulated miRNAs might be counteracted with antagomiRNA molecules (c). A partial list of dysregulated miRNAs in gliomas is depicted in Supplementary Table S1

level of miR-155, supporting the concept that characterization of the GBM patients is required before the activation of a miRNA-155 targeting approach. Therefore, the analysis of the miRNA pattern appears to be a required step in the road of personalized therapy on precision medicine based on miRNA therapeutics.

Figure 3 indicates an overall strategy for determining miRNA targets in cancer patients, on the road of personalized therapy in precision oncology. The first step (step "a") is the characterization of the miRNA profile in tumor tissues, performed with either surgery-based biopsy or liquid biopsy. The characterization of dysregulated miRNAs (down-regulated, "b" and up-regulated, "c") will be helpful for staging, prognosis of the neoplasia as well as for determining the response of the patients to drugs. In addition, the analysis of dysregulated miRNAs might allow stratifying patients with respect to expression of specific miRNAs, with the final objective to propose a therapeutic intervention (either based on anti-miRNA or miRNAreplacement approach, as outlined in Figure 1). Liquid biopsy will be the best choice to monitor the outcome of this tailored therapeutic approach ${ }^{[110]}$.

\section{PEPTIDE NUCLEIC ACID-MEDIATED TARGETING OF MICRORNAS IN GBM CELL LINES}

The studies focusing on the possible use of PNAs targeting microRNAs are few. The first report was published by Brognara et al. ${ }^{[62]}$, who found that a PNA targeting miR-221 (R8-PNA-a221), bearing an oligoarginine peptide (R8) enabling efficient uptake by glioma cells ${ }^{[58,59,62]}$, strongly inhibited miR-221-3p in U251, U373 and T98G glioma cells. This inhibition of miR-221-3p activity was associated with increased expression of the miR-221 target p27Kip1, analyzed by RT-qPCR and by Western blotting ${ }^{[62,66]}$. In a second study, Bertucci et al ${ }^{[111]}$ reported the efficient combined delivery of temozolomide and the same anti-miR221 PNA using mesoporous silica nanoparticles ${ }^{[111]}$. More recently, high levels of apoptosis on glioma cell lines were obtained following co-treatment with two PNAs, one targeting miR-221-3p, the other targeting miR-222-3p. In addition, Seo et al. ${ }^{[113]}$ showed the use of a PNA targeting miR-21 as in vivo inhibitor of glioma U87 cells.

A further example is a PNA against miR-155-5p. The possibility of obtaining clinically-relevant effects following targeting miR-155-5p with PNA-based molecules is shown in Figure 4 and elsewhere reported in the study by Milani et al. ${ }^{[109]}$, describing the synthesis and validation of a PNA targeting miR-155-5p on the temozolomide-resistant T98G glioma cell line ${ }^{[66]}$. 


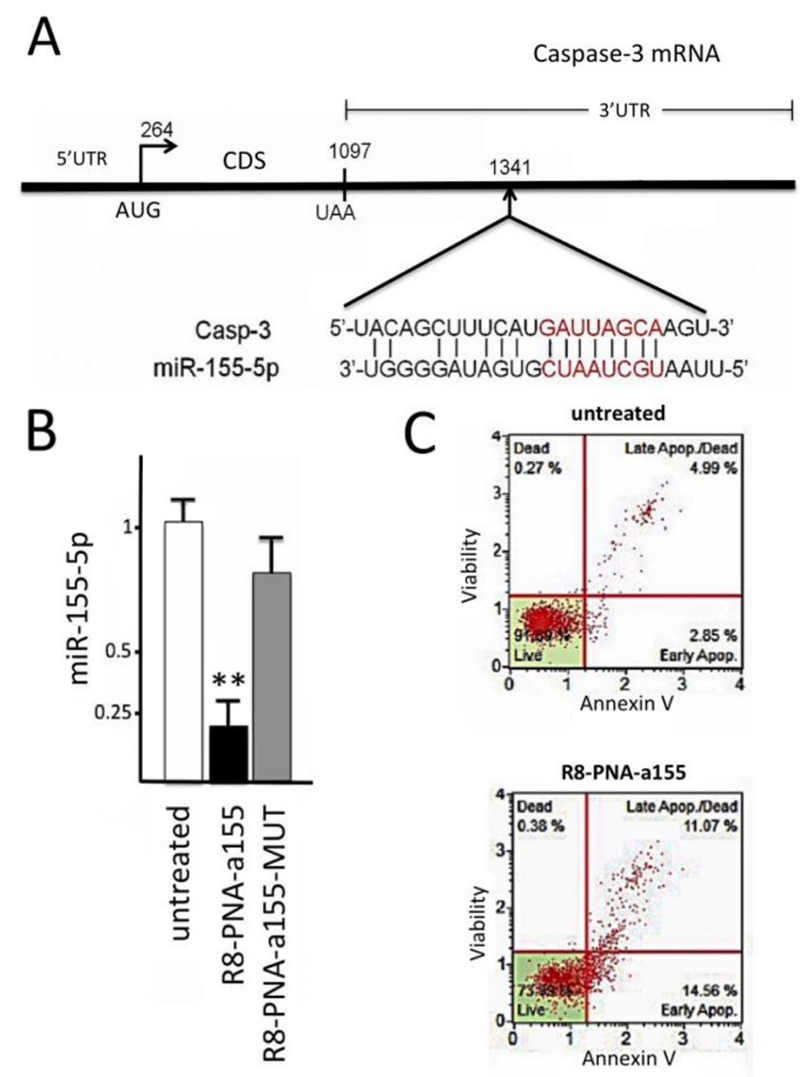

Figure 4. A. Location of a miR-155-5p binding site within the $3^{\prime} U T R$ sequence of Caspase-3 mRNA. B. Effects of cell treatment with $4 \mu M$ R8-PNA-a155 and R8-PNA-a155-MUT for $48 \mathrm{~h}$ on the miR-155-5p hybridization signal. C. Increase of T98G apoptotic cells after treatment for $48 \mathrm{~h}$ with $4 \mu \mathrm{M}$ R8-PNA-a155. Modified from Milani et al. ${ }^{[109]}$

For efficient delivery, the PNA was conjugated with an octoarginine tail (R8-PNA-a155). Apoptosis was analyzed, and the effect of this PNA was associated with a reversion of drug-resistance phenotype. The specificity of the PNA effects at the cellular level was analyzed by RT-qPCR [see Figure 4B], suggesting that the effects of R8-PNA-a155 are specific. The studies on apoptosis [Figure 4C] confirmed that the R8PNA-a155 demonstrated the pro-apoptotic effects, inducing apoptosis of TMZ-treated T98G cells.

\section{FINAL REMARKS ON MIRNA THERAPEUTICS BASED ON PNA MOLECULES: FROM THE PAST}

\section{TO FUTURE THERAPEUTIC APPLICATIONS}

The data available on the recent literature support the concept that the anti-miRNA strategy [see Figure 1] could lead to therapeutic relevant inhibition of miRNA dependent effects and that PNA-based anti-miRNA molecules are very promising reagents to regulate tumor cell growth. Further research on PNA analogues to increase efficiency of delivery, stability and control of intracellular distribution for specific targets, i.e., mature miRNA, pre-miRNA or pri-miRNA, are further steps for the selection of best candidate drugs. Finally, the studies on miRNA targeting strongly indicate that multiple miRNA targeting, might lead to significant improvement in the efficacy of the treatment. This last conclusion supports also the concept of designing multifunctional PNA-containing systems enabling to perform targeting of different mRNA sequences.

Considering PNAs as anti-miRNA reagents, it should be underlined that one of the most important challenges in PNAs technology is their delivery to cells ${ }^{[114,115]}$, in particular their low uptake by eukaryotic cells. In order to solve this drawback, several approaches have been considered. One of the several approaches 
A
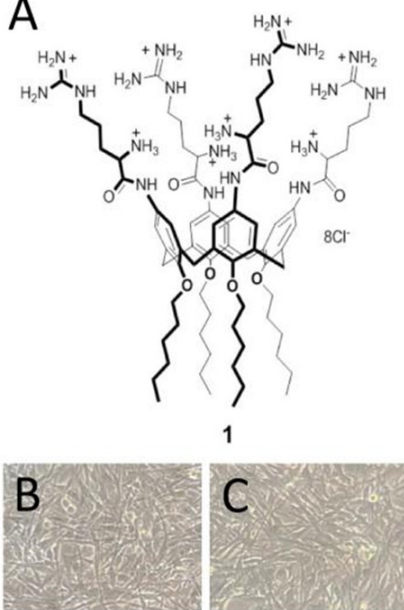

$(-)$

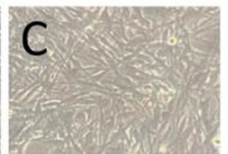

compound 1

Figure 5. A: Structure of the macrocyclic multivalent tetraargininocalix[4]arene $\mathbf{1}$ used as non-covalent vector for anti-miRNA PNAs; B,C: Effects of compound 1 on morphology of U251 glioma cells: lack of cytotoxic effects. D. Effects of free PNA (a221-PNA) and a221-PNA delivered with compound $\mathbf{1}$ on miR-221-3p in treated U251 cells. Inhibition of miR-221-3p expression is obtained only when a221-PNA is vehiculated by compound $\mathbf{1}$. Modified from Gasparello et al. ${ }^{[125]}$

undertaken to solve this issue is the conjugation with carrier peptides ${ }^{[116-118]}$, in particular those sensitive to microenvironment changes ${ }^{[11]}$; anti-miRNA activity was indeed observed for instance by conjugation of PNAs to polyarginine (poly-R) tails ${ }^{[58,59,62]}$ or by modification of the PNA backbone with cationic amino acid side chain $s^{[58,119]}$. An alternative strategy to chemical modification of PNAs is the use of carriers able to perform non-covalent and reversible interactions with the PNA structure.

In this context, it was actually already explored the delivery of PNAs and PNA derivatives or analogues with liposomes ${ }^{[120]}$, polymer nanoparticles ${ }^{[121]}$ and pseudovirions ${ }^{[122]}$, and by co-transfection with partially complementary $\mathrm{DNA}^{[123]}$. Inorganic nanocarriers, such as nanozeolites ${ }^{[124]}$ or mesoporous silica nanoparticles ${ }^{[111]}$ have been also used for cellular delivery of PNAs, maintain their biological functions. Recently, we have reported results relative to the delivery ability of a macrocyclic multivalent tetraargininocalix ${ }^{[4]}$ arene "1" [Figure 5].

In conclusion, several studies demonstrate that efficiently delivered PNAs might be of great interest in the inhibition of miRNA activity. This open new and still unexplored avenues to non-viral gene therapy, especially when PNA-based strategies to target multiple miRNA sequences will be available ${ }^{[126]}$. In consideration of the high patient-to-patient variability of the miRNome, multiple miRNA targeting should be considered a key feature in the road of personalized therapy in precision medicine.

As far as delivered PNAs in vivo to experimental models of GBM, local delivery of nanoparticles should be considered a promising therapeutic strategy that bypasses the blood-brain barrier, minimizes systemic toxicity, and enhances intracranial drug distribution and retention. In this respect, Seo et al. ${ }^{[113]}$ developed nanoparticles loaded with PNAs inhibiting miR-21, a microRNA overexpressed in GBM and retaining oncogenic features. These authors employed a block copolymer of poly(lactic acid) and hyperbranched polyglycerol to deliver an anti-miR-21 PNA, showing that efficient intracellular delivery was facilitated, leading to miR-21 suppression and PTEN upregulation and apoptosis of human GBM cells. This antimiR-21 PNA was also administered by convection-enhanced delivery to animals with intracranial gliomas, inducing significant miR-21 knockdown and chemosensitization, resulting in improved survival when combined with chemotherapy ${ }^{[113]}$. This study demonstrates the feasibility and promise of local administration 
of nanoparticles carrying an anti-miR-21 PNAs for the development of protocols for adjuvant therapy for GBM. Interestingly, the delivered PNAs were found to cause long-term survival in treated mice at a level much higher with respect to antisense RNAs.

\section{DECLARATIONS}

\section{Authors' contributions}

Revised and approved the final manuscript: Gambari R, Gasparello J, Finotti A

Wrote the manuscript, performed the literature search, and critically analyzed the existing literature: Gambari R, Gasparello J, Finotti A

Designed the figures and created the tables: Gambari R, Finotti A

\section{Availability of data and materials}

Not Applicable.

\section{Financial support and sponsorship}

This work was supported by the European Union (EU) Horizon 2020 Research and Innovation Programme (GA \#633937) project ULTRAsensitive PLAsmonic devices for early CAncer Diagnosis (ULTRAPLACAD), and by Associazione Italiana per la Ricerca sul Cancro (AIRC) (IG\#13575 to RG) . This study was also supported by the Interuniversity Consortium for the Biotechnology, Italy.

\section{Conflicts of interest}

All authors declared that there are no conflicts of interest.

\section{Ethical approval and consent to participate}

Not applicable.

\section{Consent for publication}

Not applicable.

\section{Copyright}

The Author(s) 2019.

\section{REFERENCES}

1. Sontheimer EJ, Carthew RW. Silence from within: endogenous siRNAs and miRNAs. Cell 2005;122:9-12.

2. Filipowicz W, Jaskiewicz L, Kolb FA, Pillai RS. Post-transcriptional gene silencing by siRNAs and miRNAs. Curr Opin Struct Biol 2005; 15:331-41.

3. Alvarez-Garcia I, Miska EA. MicroRNA functions in animal development and human disease. Development 2005;132:4653-62.

4. He L, Hannon GJ. MicroRNAs: small RNAs with a big role in gene regulation. Nat Rev Genet 2004;5:522-31.

5. Lim LP, Lau NC, Garrett-Engele P, Grimson A, Schelter JM, et al. Microarray analysis shows that some microRNAs downregulate large numbers of target mRNAs. Nature 2005;433:769-73.

6. Chou CH, Shrestha S, Yang CD, Chang NW, Lin YL, et al. miRTarBase update 2018: a resource for experimentally validated microRNAtarget interactions. Nucleic Acids Res 2017;46:D296-D302.

7. Griffiths-Jones S. The microRNA Registry. Nucleic Acids Res 2004;32:D109-11.

8. Maracaja-Coutinho V, Paschoal AR, Caris-Maldonado JC, Borges PV, Ferreira AJ, et al. Noncoding RNAs Databases: Current Status and Trends. Methods Mol Biol 2019;1912:251-85.

9. Monga I, Kumar M. Computational resources for prediction and analysis of functional miRNA and their targetome. Methods Mol Biol 2019;1912:215-50.

10. Gambari R, Fabbri E, Borgatti M, Lampronti I, Finotti A, et al. Targeting microRNAs involved in human diseases: a novel approach for modification of gene expression and drug development. Biochem Pharmacol 2011;82:1416-29.

11. Cheng CJ, Bahal R, Babar IA, Pincus Z, Barrera F, et al. MicroRNA silencing for cancer therapy targeted to the tumour microenvironment. Nature 2015;518:107-10. 
12. Taylor MA, Schiemann WP. Therapeutic Opportunities for Targeting microRNAs in Cancer. Mol Cell Ther 2014;2:1-13.

13. Nana-Sinkam SP, Croce CM. Clinical applications for microRNAs in cancer. Clin Pharmacol Ther 2013;93:98-104.

14. Piva R, Spandidos DA, Gambari R. From microRNA functions to microRNA therapeutics: novel targets and novel drugs in breast cancer research and treatment. Int J Oncol 2013;43:985-94

15. Gambari R, Brognara E, Spandidos DA, Fabbri E. Targeting oncomiRNAs and mimicking tumor suppressor miRNAs: New trends in the development of miRNA therapeutic strategies in oncology (Review). Int J Oncol 2016;49:5-32.

16. Finotti A, Allegretti M, Gasparello J, Giacomini P, Spandidos DA, et al. Liquid biopsy and PCR-free ultrasensitive detection systems in oncology. Int J Oncol 2018;53:1395-434.

17. Mollaei H, Safaralizadeh R, Rostami Z. MicroRNA replacement therapy in cancer. J Cell Physiol 2019; in press.

18. Pekarsky Y, Croce CM. Noncoding RNA genes in cancer pathogenesis. Adv Biol Regul 2018;71:219-23.

19. Kogure A, Kosaka N, Ochiya T. Cross-talk between cancer cells and their neighbors via miRNA in extracellular vesicles: an emerging player in cancer metastasis. J Biomed Sci 2019;26:7.

20. Montgomery RL, Yu G, Latimer PA, Stack C, Robinson K, et al. MicroRNA mimicry blocks pulmonary fibrosis. EMBO Mol Med 2014;6:1347-56.

21. Bader AG. miR-34-a microRNA replacement therapy is headed to the clinic. Front Genet 2012;3:120.

22. Kwekkeboom RF, Lei Z, Doevendans PA, Musters RJ, Sluijter JP. Targeted delivery of miRNA therapeutics for cardiovascular diseases: opportunities and challenges. Clin Sci (Lond) 2014;127:351-65.

23. Lee YS, Dutta A. The tumor suppressor microRNA let-7 represses the HMGA2 oncogene. Genes Dev 2007;21:1025-30.

24. Sampson VB, Rong NH, Han J, Yang Q, Aris V, et al. MicroRNA let-7a down-regulates MYC and reverts MYC induced growth in burkitt lymphoma cells. Cancer Res 2007;67:9762-70.

25. Weiler J, Hunziker J, Hall J. Anti-miRNA oligonucleotides (AMOs): ammunition to target miRNAs implicated in human disease? Gene Ther 2006;13:496-502.

26. Lu Y, Xiao J, Lin H, Bai Y, Luo X, et al. A single antimicroRNA antisense oligodeoxyribonucleotide (AMO) targeting multiple microRNAs offers an improved approach for microRNA interference. Nucleic Acids Res 2009;37:e24.

27. Lennox KA, Behlke MA. Chemical modification and design of antimiRNA oligonucleotides. Gene Ther 2011;18:1111-20.

28. Obad S, dos Santos CO, Petri A, Heidenblad M, Broom O, et al. Silencing of microRNA families by seed-targeting tiny LNAs. Nat Genet 2011;43:371-8.

29. Elmén J, Lindow M, Schütz S, Lawrence M, Petri A, et al. LNA-mediated microRNA silencing in non-human primates. Nature 2008;452:896-9.

30. Stenvang J, Silahtaroglu AN, Lindow M, Elmen J, Kauppinen S. The utility of LNA in microRNA based cancer diagnostics and therapeutics. Semin Cancer Biol 2008;18:89-102.

31. Staedel C, Varon C, Nguyen PH, Vialet B, Chambonnier L, et al. Inhibition of gastric tumor cell growth using seed-targeting LNA as specific, long-lasting MicroRNA inhibitors. Mol Ther Nucleic Acids 2015;4:e246.

32. Ebert MS, Neilson JR, Sharp PA. MicroRNA sponges: competitive inhibitors of small RNAs in mammalian cells. Nat Methods 2007;4:721-6.

33. Ebert MS, Sharp PA. MicroRNA sponges: progress and possibilities. RNA 2010;16:2043-50.

34. Kluiver J, Gibcus JH, Hettinga C, Adema A, Richter MK, et al. Rapid generation of microRNA sponges for microRNA inhibition. PLoS One 2012; 7:e29275.

35. Kluiver J, Slezak-Prochazka I, Smigielska-Czepiel K, Halsema N, Kroesen BJ, et al. Generation of miRNA sponge constructs. Methods 2012;58:113-7.

36. Li KC, Chang YH, Yeh CL, Hu YC. Healing of osteoporotic bone defects by baculovirus- engineered bone marrow-derived MSCs expressing MicroRNA sponges. Biomaterials 2015;74:155-66.

37. de Melo Maia B, Ling H, Monroig P, Ciccone M, Soares FA, et al. Design of a miRNA sponge for the miR-17 miRNA family as a therapeutic strategy against vulvar carcinoma. Mol Cell Probes 2015;29:420-6.

38. Tay FC, Lim JK, Zhu H, Lin LC, Wang S. Using artificial microRNA sponges to achieve microRNA loss-of-function in cancer cells. Adv Drug delivery Rev 2015;81:117-27.

39. Liu Y, Han Y, Zhang H, Nie L, Jiang Z, et al. Synthetic miRNA-mowers targeting miR- 183-96-182 cluster or miR-210 inhibit growth and migration and induce apoptosis in bladder cancer cells. PLoS One 2012;7:e52280.

40. Wang Z. The principles of MiRNA-masking antisense oligonucleotides technology. Methods Mol Biol 2011;676:43-9.

41. Bak RO, Hollensen AK, Mikkelsen JG. Managing microRNAs with vector-encoded decoy-type inhibitors. Mol Ther 2013;21:1478-85.

42. Murakami K, Miyagishi M. Tiny masking locked nucleic acids effectively bind to mRNA and inhibit binding of microRNAs in relation to thermodynamic stability. Biomed Rep 2014;2:509-12.

43. Das S. Identification and targeting of microRNAs modulating acquired chemotherapy resistance in Triple negative breast cancer (TNBC): A better strategy to combat chemoresistance. Med Hypotheses 2016;96:5-8.

44. Chan JK, Blansit K, Kiet T, Sherman A, Wong G, et al. The inhibition of miR-21 promotes apoptosis and chemosensitivity in ovarian cancer. Gynecol Oncol 2014;132:739-44.

45. Feng R, Dong L. Knockdown of microRNA-127 reverses adriamycin resistance via cell cycle arrest and apoptosis sensitization in adriamycin-resistant human glioma cells. Int J Clin Exp Pathol 2015;8:6107-16.

46. Li W, Guo F, Wang P, Hong S, Zhang C. miR-221/222 confers radioresistance in glioblastoma cells through activating Akt independent of PTEN status. Curr Mol Med 204;14:185-95. 
47. Chen L, Zhang J, Han L, Zhang A, Zhang C, et al. Downregulation of miR-221/222 sensitizes glioma cells to temozolomide by regulating apoptosis independently of p53 status. Oncol Rep 2012;27:854-60.

48. Xie Q, Yan Y, Huang Z, Zhong X, Huang L. MicroRNA-221 targeting PI3-K/Akt signaling axis induces cell proliferation and resistance in human glioblastoma. Neuropathology 2014;34:455-64.

49. Nielsen PE, Egholm M, Berg RH, Buchardt O. Sequence-selective recognition of DNA by strand displacement with a thyminesubstituted polyamide. Science 1991;254:1497-500.

50. Nielsen PE. Targeting double stranded DNA with peptide nucleic acid (PNA). Curr Med Chem 2001;8:545-50.

51. Borgatti M, Lampronti I, Romanelli A, Pedone C, Saviano M, et al. Transcription factor decoy molecules based on a peptide nucleic acid (PNA)-DNA chimera mimicking Sp1 binding sites. J Biol Chem 2003;278:7500-9.

52. Gambari R. Peptide-nucleic acids (PNAs): a tool for the development of gene expression modifiers. Curr Pharm Des 2001;7:1839-62.

53. Gambari R. Biological activity and delivery of peptide nucleic acids (PNA)-DNA chimeras for transcription factor decoy (TFD) pharmacotherapy. Curr Med Chem 2004;11:1253-63.

54. Nielsen PE. Peptide nucleic acids (PNA) in chemical biology and drug discovery. Chem Biodivers 2010;7:786-804.

55. Nielsen PE. Gene targeting and expression modulation by peptide nucleic acids (PNA). Curr Pharm Des 2010;16:3118-23.

56. Gambari R, Borgatti M, Bezzerri V, Nicolis E, Lampronti I, et al. Decoy oligodeoxyribonucleotides and peptide nucleic acids-DNA chimeras targeting nuclear factor kappa-B: inhibition of IL-8 gene expression in cystic fibrosis cells infected with Pseudomonas aeruginosa. Biochem Pharmacol 2010;80:1887-94.

57. Pandey VN, Upadhyay A, Chaubey B. Prospects for antisense peptide nucleic acid (PNA) therapies for HIV. Expert Opin Biol Ther 2009;9:975-89.

58. Manicardi A, Fabbri E, Tedeschi T, Sforza S, Bianchi N, et al. Cellular Uptakes, biostabilities and anti-miR-210 activities of chiral Arginine-PNAs in leukaemic K562 cells. Chembiochem 2012;13:1327-37.

59. Fabbri E, Manicardi A, Tedeschi T, Sforza S, Bianchi N, et al. Modulation of the biological activity of microRNA-210 with peptide nucleic acids (PNAs). ChemMedChem 2011;6:2192-202.

60. Fabani MM, Gait MJ. MiR-122 targeting with LNA/2'-O-methyl oligonucleotide mixmers, peptide nucleic acids (PNA), and PNApeptide conjugates. RNA 2008:14:336-46.

61. Fabani MM, Abreu-Goodger C, Williams D, Lyons PA, Torres AG, et al. Efficient inhibition of miR-155 function in vivo by peptide nucleic acids. Nucleic Acids Research 2010;38:4466-75.

62. Brognara E, Fabbri E, Aimi F, Manicardi A, Bianchi N, et al. Peptide nucleic acids targeting miR-221 modulate p27Kip1 expression in breast cancer MDA-MB-231 cells. Int J Oncol 2012;41:2119-27.

63. Manicardi A, Gambari R, de Cola L, Corradini R. Preparation of Anti-miR PNAs for Drug Development and Nanomedicine. Methods Mol Biol 2018;1811:49-63.

64. Gupta A, Quijano E, Liu Y, Bahal R, Scanlon SE, et al. Anti-tumor Activity of miniPEG- $\gamma$-Modified PNAs to Inhibit MicroRNA-210 for Cancer Therapy. Mol Ther Nucleic Acids 2017;9:111-9.

65. Yan LX, Wu QN, Zhang Y, Li YY, Liao DZ, et al. Knockdown of miR-21 in human breast cancer cell lines inhibits proliferation, in vitro migration and in vivo tumor growth. Breast Cancer Res 2011;13:R2.

66. Brognara E, Fabbri E, Bazzoli E, Montagner G, Ghimenton C, et al. Uptake by human glioma cell lines and biological effects of a peptide-nucleic acids targeting miR-221. J Neurooncol 2014;118:19-28.

67. von Neubeck C, Seidlitz A, Kitzler HH, Beuthien-Baumann B, Krause M. Glioblastoma multiforme: emerging treatments and stratification markers beyond new drugs. Br J Radiol 2015;88:20150354.

68. Buczkowicz P, Hawkins C. Pathology, molecular genetics, and epigenetics of diffuse intrinsic pontine glioma. Front Oncol $2015 ; 5: 147$.

69. Pace A, Dirven L, Koekkoek JAF, Golla H, Fleming J, et al. European association for neuro-oncology (EANO) guidelines for palliative care in adults with glioma. Lancet Oncol 2017;18:e330-40.

70. Polivka J, Polivka J, Holubec L, Kubikova T, Priban V, et al. Advances in experimental targeted therapy and immunotherapy for patients with glioblastoma multiforme. Anticancer Res 2017;7:21-33.

71. Abbruzzese C, Matteoni S, Signore M, Cardone L, Nath K, et al. Drug repurposing for the treatment of glioblastoma multiforme. J Exp Clin Cancer Res 2017;36:169.

72. Artene SA, Tuţă C, Dragoi A, Alexandru O, Stefana Oana P, et al. Current and emerging EGFR therapies for glioblastoma. J Immunoassay Immunochem 2018;39:1-11.

73. Popescu AM, Alexandru O, Brindusa C, Purcaru SO, Tache DE, et al. Targeting the VEGF and PDGF signaling pathway in glioblastoma treatment. Int J Clin Exp Pathol 2015;8:7825-37.

74. Trojan J, Cloix JF, Ardourel MY, Chatel M, Anthony DD. Insulin-like growth factor type I biology and targeting in malignant gliomas. Neuroscience 2007;145:795-811.

75. Cuevas P, Carceller F, Angulo J, González-Corrochano R, Cuevas-Bourdier A, et al. Antiglioma effects of a new, low molecular mass, inhibitor of fibroblast growth factor. Neurosci Lett 2011;491:1-7.

76. McGranahan T, Therkelsen KE, Ahmad S, Nagpal S. Current State of Immunotherapy for Treatment of Glioblastoma. Curr Treat Options Oncol 2019;20:24.

77. Castro-Gamero AM, Pezuk JA, Brassesco MS, Tone LG. G2/M inhibitors as pharmacotherapeutic opportunities for glioblastoma: the old, the new, and the future. Cancer Biol Med 2018;15:354-74.

78. Krichevsky AM, Uhlmann EJ. Oligonucleotide therapeutics as a new class of drugs for malignant brain tumors: targeting mRNAs, regulatory RNAs, mutations, combinations, and beyond. Neurotherapeutics 2019; In Press. 
79. Geraldo LHM, Garcia C, da Fonseca ACC, Dubois LGF, de Sampaio E, et al. Glioblastoma therapy in the age of molecular medicine. Trends Cancer 2019;5:46-65.

80. Anjum K, Shagufta BI, Abbas SQ, Patel S, Khan I, et al. Current status and future therapeutic perspectives of glioblastoma multiforme (GBM) therapy: A review. Biomed Pharmacother 2017;92:681-9.

81. Lozada-Delgado EL, Grafals-Ruiz N, Vivas-Mejía PE. RNA interference for glioblastoma therapy: Innovation ladder from the bench to clinical trials. Life Sci 2017;188:26-36.

82. Touat M, Idbaih A, Sanson M, Ligon KL. Glioblastoma targeted therapy: updated approaches from recent biological insights. Ann Oncol 2017; 28:1457-72.

83. Hermansen SK, Kristensen BW. MicroRNA biomarkers in glioblastoma. J Neurooncol 2013;114:13-23.

84. Khalil S, Fabbri E, Santangelo A, Bezzerri V, Cantù C, et al. miRNA array screening reveals cooperative MGMT-regulation between miR-181d-5p and miR-409-3p in glioblastoma. Oncotarget 2016;7:28195-206.

85. Chan XH, Nama S, Gopal F, Rizk P, Ramasamy S, et al. Targeting glioma stem cells by functional inhibition of a prosurvival oncomiR-138 in malignant gliomas. Cell Rep 2012;2:591-602.

86. Li C, Sun J, Xiang Q, Liang Y, Zhao N, et al. Prognostic role of microRNA-21 expression in gliomas: a meta-analysis. J Neurooncol 2016;130:11-7.

87. Beyer S, Fleming J, Meng W, Singh R, Haque SJ, et al. The Role of miRNAs in Angiogenesis, Invasion and Metabolism and Their Therapeutic Implications in Gliomas. Cancers (Basel) 2017;9:E85.

88. Wang Y, Wang X, Zhang J, Sun G, Luo H, et al. MicroRNAs involved in the EGFR/PTEN/AKT pathway in gliomas. J Neurooncol 2012;106:217-24.

89. Regazzo G, Terrenato I, Spagnuolo M, Carosi M, Cognetti G, et al. A restricted signature of serum miRNAs distinguishes glioblastoma from lower grade gliomas. J Exp Clin Cancer Res 2016;35:124.

90. Areeb Z, Stylli SS, Koldej R, Ritchie DS, Siegal T, et al. MicroRNA as potential biomarkers in Glioblastoma. J Neurooncol 2015;125:23748.

91. Ouyang Q, Xu L, Cui H, Xu M, Yi L. MicroRNAs and cell cycle of malignant glioma. Int J Neurosci 2016;126:1-9.

92. Yan Z, Che S, Wang J, Jiao Y, Wang C, et al. miR-155 contributes to the progression of glioma by enhancing Wnt/ $\beta$-catenin pathway. Tumour Biol 2015;36:5323-31.

93. Yang L, Li C, Liang F, Fan Y, Zhang S. MiRNA-155 promotes proliferation by targeting caudal-type homeobox 1 (CDX1) in glioma cells. Biomed Pharmacother 2017;95:1759-64.

94. Costa PM, Cardoso AL, Mano M, de Lima MC. MicroRNAs in glioblastoma: role in pathogenesis and opportunities for targeted therapies. CNS Neurol Disord Drug Targets 2015;14:222-38.

95. Chen L, Kang C. miRNA interventions serve as 'magic bullets' in the reversal of glioblastoma hallmarks. Oncotarget 2015;6:38628-42.

96. Wang H, Xu T, Jiang Y, Yan Y, Qin R, et al. MicroRNAs in human glioblastoma: from bench to beside. Front Biosci (Landmark Ed) 2015;20:105-18.

97. Piwecka M, Rolle K, Belter A, Barciszewska AM, Żywicki M, et al. Comprehensive analysis of microRNA expression profile in malignant glioma tissues. Mol Oncol 2015; 9:1324-40.

98 Banelli B, Forlani A, Allemanni G, Morabito A, Pistillo MP, et al. MicroRNA in Glioblastoma: An Overview. Int J Genomics 2017;2017:7639084.

99. Ciafrè SA, Galardi S, Mangiola A, Ferracin M, Liu CG, et al. Extensive modulation of a set of microRNAs in primary glioblastoma. Biochem Biophys Res Commun 2005;334:1351-8.

100. Santangelo A, Imbrucè P, Gardenghi B, Belli L, Agushi R, et al. A microRNA signature from serum exosomes of patients with glioma as complementary diagnostic biomarker. J Neurooncol 2018;136:51-62.

101. Zhao H, Shen J, Hodges TR, Song R, Fuller GN, et al. Serum microRNA profiling in patients with glioblastoma: a survival analysis. Mol Cancer 2017;16:59.

102. Liu S, Yin F, Zhang J, Wicha MS, Chang AE, et al. Regulatory roles of miRNA in the human neural stem cell transformation to glioma stem cells. J Cell Biochem 2014;115:1368-80.

103. D'Urso PI, D'Urso OF, Storelli C, Mallardo M, Gianfreda CD, et al. miR-155 is up- regulated in primary and secondary glioblastoma and promotes tumour growth by inhibiting GABA receptors. Int J Oncol 2012; 41:228-34.

104. Ling N, Gu J, Lei Z, Li M, Zhao J, Zhang HT, Li X. microRNA-155 regulates cell proliferation and invasion by targeting FOXO3a in glioma. Oncol Rep. 2013 Nov;30(5):2111-8.

105. Zhou J, Wang W, Gao Z, Peng X, Chen X, et al. MicroRNA-155 promotes glioma cell proliferation via the regulation of MXI1. PLoS One 2013;8:e83055.

106. Meng W, Jiang L, Lu L, Hu H, Yu H, et al. Anti-miR-155 oligonucleotide enhances chemosensitivity of U251 cell to taxol by inducing apoptosis. Cell Biol Int 2012;36:653-9.

107. Sun J, Shi H, Lai N, Liao K, Zhang S, et al. Overexpression of microRNA-155 predicts poor prognosis in glioma patients. Med Oncol 2014;31:911.

108. Zhou Y, Wang X, Liu Z, Huang X, Li X, et al. Prognostic role of microRNA-155 expression in gliomas: A meta-analysis. Clin Neurol Neurosurg 2019;176:103-9.

109. Milani R, Brognara E, Fabbri E, Manicardi A, Corradini R, et al. Targeting miR-155-5p and miR-221-3p by peptide nucleic acids induces Caspase-3 activation and apoptosis in temozolomide-resistant T98G glioma cells. Int J Oncol 2019; in press.

110. Finotti A, Allegretti M, Gasparello J, Giacomini P, Spandidos DA, et al. Liquid biopsy and PCR-free ultrasensitive detection systems in 

oncology (Review). Int J Oncol 2018;53:1395-434.

111. Bertucci A, Prasetyanto EA, Septiadi D, Manicardi A, Brognara E, et al. Combined delivery of temozolomide and anti-mir221 PNA using mesoporous silica nanoparticles induces apoptosis in resistant glioma cells. Small 2015;11:5687-95.

112. Brognara E, Fabbri E, Montagner G, Gasparello J, Manicardi A, et al. High levels of apoptosis are induced in human glioma cell lines by co-administration of peptide nucleic acids targeting miR-221 and miR-222. Int J Oncol 2016;48:1029-38.

113. Seo YE, Suh HW, Bahal R, Josowitz A, Zhang J, et al. Nanoparticle-mediated intratumoral inhibition of miR-21 for improved survival in glioblastoma. Biomaterials 2019;201:87-98.

114. Tomassi S, Ieranò C, Mercurio ME, Nigro E, Daniele A, et al. Cationic nucleopeptides as novel non-covalent carriers for the delivery of peptide nucleic acid (PNA) and RNA oligomers. Bioorg Med Chem 2018;26:2539-50.

115. Avitabile C, Accardo A, Ringhieri P, Morelli G, Saviano M, et al. Incorporation of naked peptide nucleic acids into liposomes leads to fast and efficient delivery. Bioconjug. Chem 2015;26:1533-41.

116. Saleh AF, Arzumanov A, Abes R, Owen D, Lebleu B, et al. Synthesis and splice- redirecting activity of branched, arginine-rich peptide dendrimer conjugates of peptide nucleic acid oligonucleotides. Bioconj Chem 2010;21:1902-11.

117. Turner Y, Wallukat G, Säälik P, Wiesner B, Pritz S, et al. Cellular uptake and biological activity of peptide nucleic acids conjugated with peptides with and without cell-penetrating ability. J Pept Sci 2010;16:71-80.

118. Hu J, Corey DR. Inhibiting gene expression with peptide nucleic acid (PNA)-peptide conjugates that target chromosomal DNA. Biochemistry 2007;46:7581-9.

119. Hnedzko D, McGee DW, Karamitas YA, Rozners E. Sequence-selective recognition of double-stranded RNA and enhanced cellular uptake of cationic nucleobase and backbone- modified peptide nucleic acids. RNA 2017;23:58-69.

120. Shiraishi T, Hamzavi R, Nielsen P E. Subnanomolar antisense activity of phosphonate- peptide nucleic acid (PNA) conjugates delivered by cationic lipids to HeLa cells. Nucleic Acids Res 2008;36:4424-32.

121. McNeer NA, Chin JY, Schleifman EB, Fields RJ, Glazer PM, et al. Nanoparticles deliver triplex-forming PNAs for site-specific genomic recombination in CD34+ human hematopoietic progenitors. Mol Ther 2011; 19:172-180.

122. Macadangdang B, Zhang N, Lund PE, Marple AH, Okabe M, et al. Inhibition of multidrug resistance by SV40 pseudovirion delivery of an antigene peptide nucleic acid (PNA) in cultured cells. PLoS One 2011; 6:e17981.

123. Hamilton SE, Simmons CG, Kathiriya IS, Corey DR. Cellular delivery of peptide nucleic acids and inhibition of human telomerase. Chem Biol 1999;6:343-51

124. Bertucci A, Lülf H, Septiadi D, Manicardi A, Corradini R, et al. Intracellular delivery of peptide nucleic acid and organic molecules using zeolite-L nanocrystals. Adv Healthc Mater 2014;3:1812-7.

125. Gasparello J, Manicardi A, Casnati A, Corradini R, Gambari R, et al. Efficient cell penetration and delivery of peptide nucleic acids by an argininocalix[4]arene. Sci Rep 2019;9:3036.

126. Jung J, Yeom C, Choi YS, Kim S, Lee E, et al. Simultaneous inhibition of multiple oncogenic miRNAs by a multi-potent microRNA sponge. Oncotarget 2015;6:20370-87. 